\title{
Abnormal evoked potential latencies in amblyopia
}

\author{
SAMUEL SOKOL \\ From the Department of Ophthalmology, New England Medical Center, and \\ Tufts University School of Medicine, Boston, USA
}

SUMMARY The latency of the first $\left(\mathrm{P}_{1}\right)$ and second $\left(\mathrm{P}_{2}\right)$ major positive waves of the pattern reversal visual evoked potential (VEP) for small checks (15 minutes of arc) was measured in 68 visually normal children and 32 amblyopic children with mild to moderate visual acuity losses. In the normal children there were no $P_{1}$ and $P_{2}$ interocular latency differences. The amblyopic children showed longer $P_{1}$ latencies and shorter $P_{2}$ latencies in their amblyopic eye than their normal fellow eye. These findings can be accounted for by a selective loss of the contrast-specific evoked potential mechanisms in amblyopia. The 'shorter' $P_{2}$ latency obtained from amblyopic eyes for small checks is a reflection of the luminance responses that are normally elicited by larger ( 60 minute) checks.

The amplitude of the pattern visual evoked potential (VEP) is markedly attenuated in amblyopia, particularly when the stimulus is composed of small pattern elements. ${ }^{1-5}$ While the latency of the transient pattern reversal VEP has been carefully studied in diseases of the optic nerve and anterior visual pathways, ${ }^{G \rightarrow}$ little attention has been given to the latency of the VEP in amblyopia. There are reports of increases in the latency of the first major positive wave $\left(P_{1}\right)$ of the pattern VEP in the amblyopic eye of amblyopes ${ }^{10-13}$ as well as in the normal fellow eye following occlusion, ${ }^{11}{ }^{12}$ but the increases are not as large as those found in patients with optic neuritis or multiple sclerosis. ${ }^{67}$ Of further interest is the second positive component $\left(\mathrm{P}_{2}\right)$ of the transient VEP, since it has been reported that the amplitude of $\mathrm{P}_{2}$ shows sharper spatial tuning properties than $P_{1}$ and may therefore have some relationship to amblyopia. ${ }^{14-16}$

In the present study the latency of both the early $\left(P_{1}\right)$ and late $\left(P_{2}\right)$ components of the transient pattern reversal VEP were measured in a group of visually normal children and in a group of amblyopic children with mild to moderate visual acuity losses. The amblyopic children have abnormally long $P_{1}$ latencies

Correspondence to S. Sokol. PhD. Department of Ophthalmology. Box 820. New England Medical Center. 171 Harrison Ave.. Boston. MA. 02111. USA. in their amblyopic eye but significantly shorter $P_{2}$ latencies in their amblyopic eye.

\section{Material and methods}

STIMULI AND RECORDING PROCEDURE

The pattern VEP was elicited by a checkerboard stimulus of constant mean luminance $\left(1.9 \mathrm{log} \mathrm{cd} / \mathrm{m}^{2}\right)$ which was generated by a black-and-white TV monitor. The size of the field was $12^{\circ} \times 15^{\circ}$, and the checks, which subtended 15 minutes of arc, were phase-reversed at $1 \mathrm{~Hz}$ (2 alternations/s). In order to obtain VEPs which were predominantly luminance specific, ${ }^{17} 6$ of the amblyopic children were also tested with checks subtending 60 minutes of arc. The contrast of the checks was $0 \cdot 84$. The VEP was recorded from a gold disc electrode located $1 \mathrm{~cm}$ anterior to the inion $\left(\mathrm{O}_{z}\right)$ along the midline and referenced to the ear; the other ear served as ground. Each child was seated $75 \mathrm{~cm}$ from the pattern stimulus at a table with a chin rest, and optical correction, if needed, was used. An observer remained in the shielded room with the child during testing to monitor fixation and to control the operation of the averager by means of a remote switch. The averaging programme contained an artefact rejection routine which eliminated sweeps containing large DC shifts and muscle potentials. The band pass of the amplifiers was 1 and $35 \mathrm{~Hz}$, and the total analysis time 

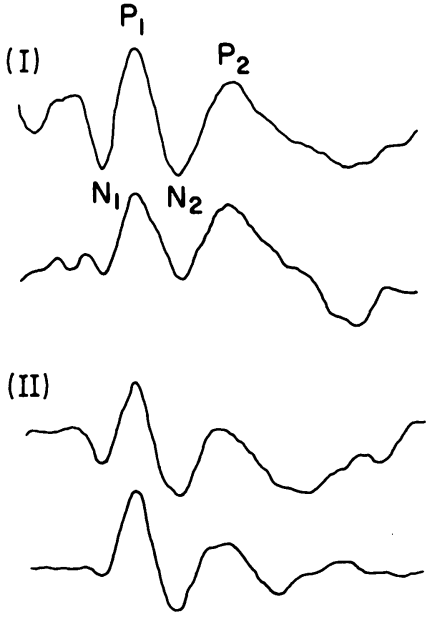
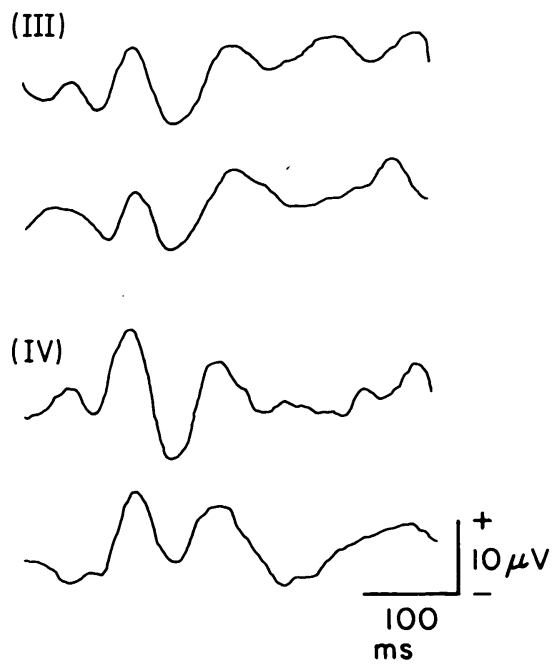

Fig. 1 Transient pattern reversal $V E P s$ obtained from four visually normal children. The checkerboard pattern stimulus was composed of 15-minute checks alternating at $1 \mathrm{~Hz}$ (2 reversals/s). was $410 \mathrm{~ms}$. All data were stored on a floppy diskette and retrieved for subsequent analysis of peak latencies.

\section{SUBJECTS AND PATIENTS}

Pattern reversal VEPs were recorded from 68 visually normal children between 3 and $7 \cdot 5$ years of age (mean 4.8 years) and from 32 amblyopic children between 2.7 and 10 years of age (mean 6.75 years). The majority of the amblyopic children were strabismic (22 esotropes, 6 exotropes). The remainder were anisometropic $(n=6)$ or microtropic $(n=2)$. All of the amblyopic children had a history of occlusion therapy for their amblyopia which had been only partially successful. None of the children were being actively treated at the time of VEP measurement. Visual acuity in the amblyopic eyes ranged from $6 / 12$ to $6 / 60$; 20 of the 32 children had acuities of between $6 / 12$ and $6 / 18$. Nine amblyopic children had parafoveal eccentric fixation. Visual screening of the normal children included measurement of subjective visual acuity at near and distance, versions and ductions, and fusion by Fly or Worth 4 dot test. Each of the amblyopic children was examined by a paediatric ophthalmologist and an orthoptist.

\section{Results}

Records obtained from 4 visually normal children are shown in Fig. 1. The transient VEP from each eye shows the typical waveforms obtained with a pattern reversal stimulus. The normal wave consists of an initial negative deflection at $85-95 \mathrm{~ms}\left(\mathrm{~N}_{1}\right)$, a positive wave at $100-120 \mathrm{~ms}\left(\mathrm{P}_{1}\right)$, a second negative wave at 160-180 ms $\left(\mathrm{N}_{2}\right)$, and a second positive wave at 180
$220 \mathrm{~ms}\left(\mathrm{P}_{2}\right)$. Records obtained from 4 amblyopic children are shown in Fig. 2. The VEP from the normal eye of each amblyopic child (upper record of each pair) is similar to the VEP obtained from the visually normal children. In the amblyopic eye of subjects VI and VIII there is a slight increase in $P_{1}$ latency. In the amblyopic eye of subjects V, VI, and VII (lower record) the peak latency of the second positive wave $\left(\mathrm{P}_{2}\right)$ is shorter than in the normal fellow eye. The $P_{2}$ latency for the amblyopic eye of subject VIII is so short that it gives the waveform the appearance of a single component which peaks between the latency for $P_{1}$ and $P_{2}$ for her normal eye.

Fig. 3 shows the mean interocular difference for the 3 major components of the VEP recorded from the 68 visually normal children and from the 32 amblyopic children. Statistical analysis was confined to nonparametric techniques, since preliminary examination of the data revealed that the latency values from the amblyopes were not normally distributed and the variances were heterogeneous. ${ }^{18}$ Analysis of the interocular latencies from the normal children by the Wilcoxón matched-pairs signed-rank test showed no significant differences for any of the 3 components. Analysis of the interocular latencies for the amblyopic children showed a small but significant latency difference $(p<0.05)$ for $P_{1}$; latency for the amblyopic eye was slightly longer (mean difference $=$ $4 \mathrm{~ms}$ ). There was no significant interocular difference for $\mathbf{N}_{2}$. Analysis of $\mathbf{P}_{2}$ interocular latency showed a large difference between eyes (mean $=20 \mathrm{~ms}$ ); the latency from the amblyopic eye was significantly shorter $(p<0 \cdot 05)$.

An analysis of the group differences for $P_{1}, N_{2}$, and $P_{2}$ latency was also done by the Mann-Whitney $U$ 
Fig. 2 Pattern VEPs for 15-minute checks (2 reversals/s) recorded from the normal (upper record) and amblyopic (lower record) eye of 4 amblyopic children.
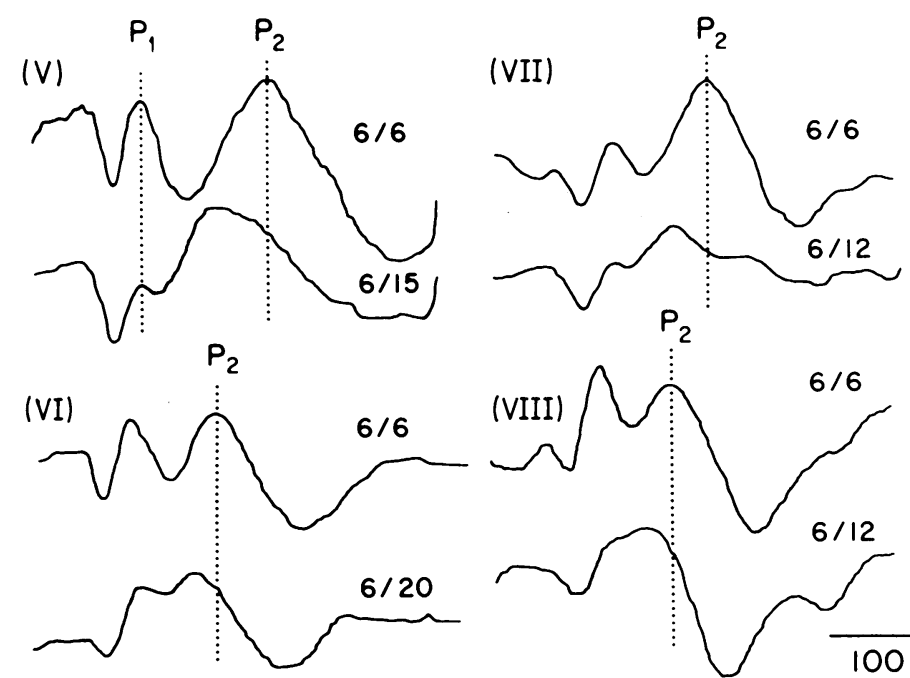

$6 / 6$

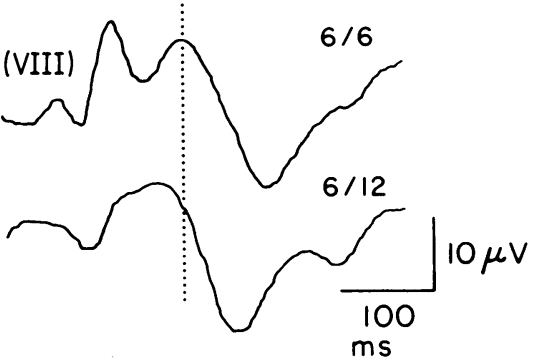

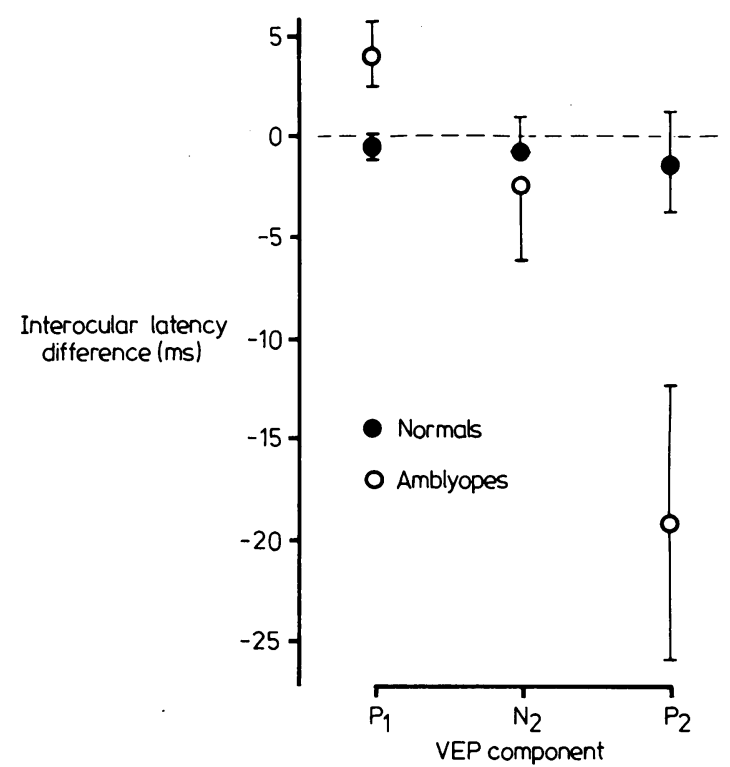

Fig. 3 Interocular latency difference for $P_{1}, N_{2}$, and $P_{2}$ in normal $(n=68)$ and amblyopic $(n=32)$ children. For the normal children the latency of the left eye was subtracted from the right eye. For amblyopic children the latency of the normal eye was subtracted from the latency of the amblyopic eye. Vertical bars indicate \pm 1 standard error of the mean; the overlapping standard errors are not shown for $\mathrm{N}_{2}$. While the absolute direction of the interocular difference is arbitrary - that is, the amblyopic eye could have been subtracted from the normal eye, resulting in a prolonged $P_{2}$ latency in the normal eye-the results shown in Fig. 4 and discussed in the text argue against this possibility. test. There were no significant differences for $P_{1}, N_{2}$, and $P_{2}$ latency when data from the normal eye of the amblyopes were compared with monocular latencies from the normal children. However, analysis of the group differences between the amblyopic eye of the amblyopes and the monocular data from the normal children showed that $P_{1}$ latency of the amblyopic eye in the amblyopes was significantly longer than the monocular $P_{1}$ latency obtained from the normal children $(p<0.05)$. There were no significant group differences for the normal and amblyopic children for $\mathrm{N}_{2}(\mathrm{p}=0 \cdot 26)$, and the $\mathrm{P}_{2}$ differences were of borderline significance $(p=0.07)$. The advantage of using the matched-pairs Wilcoxon test of interocular differences is that the between-subject variability which enters into the statistical analysis of group differences is eliminated.

Fig. 4 shows VEP waveforms obtained from one of the 6 amblyopes tested with both 15 and 60 -minute checks; the other 5 children gave similar results. The bottom record shows the VEP recorded from the amblyopic subject's normal eye for 15-minute checks; $P_{2}$ latency is $210 \mathrm{~ms}$. This is within the normal range for the $\mathrm{P}_{2}$ latency recorded from nonamblyopic children and would argue against the possibility that the normal eye of an amblyope has an abnormally prolonged $\mathrm{P}_{2}$ latency. The $\mathrm{P}_{2}$ latencies for the normal and amblyopic eye for 60-minute checks (second and third record) are the same (175 ms) and are equal to the $\mathrm{P}_{2}$ latency for 15-minute checks from the amblyopic eye (uppermost record). Thus the normal eye produces a long (and normal) $\mathrm{P}_{2}$ latency, while the latency of the VEP from the amblyopic eye for 
small checks is shorter than normal and equal to the latency obtained with large checks.

\section{Discussion}

The latency of $P_{1}$ of the transient pattern reversal VEP is a frequently measured parameter in studies of the abnormal visual system. Abnormal prolongation of $P_{1}$ is found in optic neuropathy, ${ }^{6}$ glaucoma, ${ }^{1920}$ compressive lesions of the anterior visual pathways, ${ }^{8}$ and demyelinating disease. ${ }^{7}$ In addition, nonpathological factors can also cause a prolongation of $P_{1}$ latency; these include mild to moderate refractive errors, ${ }^{21}$ miotic pupils, ${ }^{20}$ increasing age, ${ }^{22}{ }^{23}$ and decreases in the check or stripe size of the pattern stimulus. ${ }^{14-1624}$ On the other hand little attention has been given in clinical studies to the latency of the later $\mathrm{P}_{2}$ component of the transient pattern reversal VEP.

The results of the present study confirm previous reports that there is a small but statistically significant increase in $P_{1}$ latency in amblyopia. ${ }^{10-13}$ In addition the present results show that the latency of $P_{2}$ is also abnormal in amblyopia but the direction of the abnormality is opposite to that of $P_{1}$. In the amblyopic eye $\mathrm{P}_{2}$ latency is abnormally short.

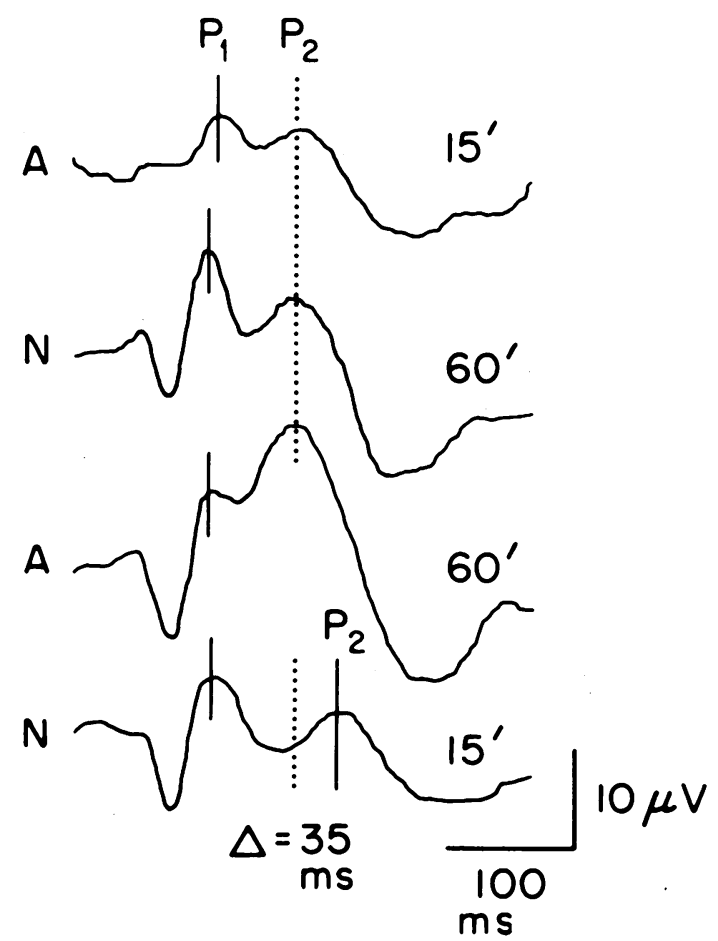

Fig. 4 Waveforms obtained from an amblyopic child with 15 and 60 minute checks: $A$, amblyopic; $N$, normal.
Several possibilities could account for these results. The shorter latency ' $P_{2}$ ' component recorded from the amblyopic eye could be arising from mechanisms that are separate and unrelated to the longer latency ' $P_{2}$ ' component in the normal eye. Another explanation is that the paradoxically faster $\mathrm{P}_{2}$ latency for small checks in an amblyopic eye is in fact a reflection of the same normal mechanism which generates the $P_{2}$ component for large checks. Support for this possibility is found in other studies of the amplitude and latency of the pattern VEP. Regan and Richards $^{17}$ reported that VEPs elicited by different check sizes are composed of different types of activity; small checks (less than 20 minutes of arc) produce responses which are predominantly contrastspecific and large checks produce responses which are predominantly the result of local luminance changes. Further, Parker and Slazen ${ }^{14-16}$ used an onset-offset sinusoidal grating to elicit VEPs and found that the latency of $\mathrm{P}_{2}$ was shortest for low spatial frequencies and increased by nearly $75 \mathrm{~ms}$ as the spatial frequency of a sinusoidal grating was increased from 0.5 to 24 cycles/degree. Similar results also occur with check stimuli; $P_{2}$ increases of $25 \mathrm{~ms}$ are seen as check size is decreased (spatial frequency is increased) from 240 minutes of arc to 7.5 minutes of arc. ${ }^{24}$ Thus large checks and/or low spatial frequency gratings produce short latency VEPs that are mainly a reflection of local luminance activity.

Since the major defect in amblyopia is a loss of contrast-specific mechanisms rather than luminance mechanisms, ${ }^{2526}$ one might expect that VEP abnormalities would be more severe with small checks. This is indeed true for the amplitude of the VEP, ${ }^{1-5}$ and, as seen in the data obtained from amblyopic children with large and small checks (Fig. 4), similar results occur with latency, particularly $P_{2}$. The latency of $\mathbf{P}_{2}$ for small checks recorded from an amblyopic eye is the same as the $P_{2}$ latency recorded with large checks from both the amblyopic and normal eye. Because of the drop-out of the middle and high spatial frequency mechanisms in amblyopia, the VEP obtained from the amblyopic eye for small checks is most likely a reflection of the luminance activity which is obtained when large checks are used to stimulate either eye.

Parker and Salzen ${ }^{14}$ have proposed that the $P_{2}$ component of the pattern VEP reflects contrastspecific mechanisms because of its sharp tuning properties when amplitude is measured and its 'susceptibility to operations which are known to affect the pattern recognition threshold.' Our finding that there is a significant effect on $\mathbf{P}_{2}$ latency in amblyopia would seem to support their notion that the late wave of the VEP is a reflection of the sustained, pattern detection system. 
I thank Drs Anne Moskowitz and Leo Towle for their assistance with data analysis and suggestions regarding the manuscript and Dr Ernie Clark for his help with the statistical analyses. This work was supported by a grant (EY-00926) from the National Eye Institute.

\section{References}

1 Spekreijse $H$, Khoe LH, van der Tweel LH. A case of amblyopia: electrophysiology and psychophysics of luminance and contrast. In: Arden GB, ed. The visual system, neurophysiology, biophysics and their clinical applications. Recent Advances in Experimental Biology and Medicine. New York: Plenum Press. 1972: 24: 141-56.

2 Sokol S. Bloom B. Visually evoked cortical responses of amblyopes to a spatially alternating stimulus. Invest Ophthalmol Visual Sci 1973; 12: 936-9.

3 Arden GB. Barnard WM, Mushin AS. Visually evoked responses in amblyopia. Br J Ophthalmol 1974; 58: 183-92.

4 Sokol S. Shaterian E. The pattern evoked cortical potential in amblyopia as an index of visual function. In: Moore S. Mein J. Stockbridge L. eds. Transactions of the Third International Orthoptic Congress. Miami: Symposia Specialists. 1976: 59-67.

5 Levi DM. Harwerth RS. Contrast evoked potentials in strabismic and anisometropic amblyopia. Invest Ophthalmol Visual Sci 1978; 17: 571-5.

6 Halliday AM. McDonald WI. Mushin J. Delayed visual evoked response in optic neuritis. Lancet 1972; i: 982-5.

7 Halliday AM, McDonald WI, Mushin J. Visual evoked response in diagnosis of multiple sclerosis. Br Med J 1973; iv: 661-4.

8 Halliday AM. Halliday E. Kriss A. McDonald WI. Mushin J. The pattern-evoked potential in compression of the anterior visual pathways. Brain 1976; 99: 357-74.

9 Sokol S. Visual evoked potentials. In: Aminoff MJ, ed. Electrodiagnosis in clinical neurologv. New York: Churchill Livingstone. 1980: 348-69.

10 Wanger P. Nilsson BY. Visual evoked responses to patternreversal stimulation in patients with amblyopia and/or defective binocular functions. Acta Ophthalmol (Kbh) 1978; 56: 617-27.

11 Arden GB. Barnard WM. Effect of occlusion on the visual evoked response in amblyopia. Trans Ophthalmol Soc UK 1980; 99: 419-26.
12 Sokol S. Pattern visual evoked potentials: their use in pediatric ophthalmology. In: Sokol S. ed. Electrophysiology and psychophysics: their use in ophthalmic diagnosis. Boston: Little. Brown. 1980: 251-68.

13 Wanger $P$. Persson HE. Visual evoked responses to patternreversal stimulation in childhood amblyopia. Acta Ophthalmol (Kbh) 1980; 58: 697-706.

14 Parker DM. Salzen EA. Latency changes in the human visual evoked response to sinusoidal gratings. Vision Res 1977; 17: 1201-4.

15 Parker DM. Salzen EA. The spatial selectivity of early and late waves within the human visual evoked response. Perception 1977; 6: 85-95.

16 Parker DM, Salzen EA, Lishman JR. Visual-evoked responses elicited by the onset and offset of sinusoidal gratings: latency. waveform and topographic characteristics. Invest Ophthalmol Visual Sci 1982: 22: 675-80.

17 Regan D. Richards W. Brightness contrast and evoked potentials. J Opt Soc Am 1973; 63: 606-11.

18 Siegel S. Nonparametric statistics for the behavioral sciences. New York: McGraw-Hill, 1956.

19 Huber C. Wagner T. Electrophysiological evidence for glaucomatous lesions in the optic nerve. Ophthalmic Res 1978; 10: 22-9.

20 Sokol S. Domar A. Moskowitz A. Schwartz B. Pattern evoked potential latency and contrast sensitivity in glaucoma and ocular hypertension. In: Spekreijse H. Apkarian PA. eds. Doc Ophthalmol (Proc Ser) 1981; 27: 79-85.

21 Sokol S. Moskowitz A. Effect of retinal blur on the peak latency of the pattern-evoked potential. Vision Res 1981: 21: 1279-86.

22 Celesia GG, Daly RF. Effects of aging on visual evoked responses. Arch Neurol 1977: 34: 403-7.

23 Sokol S. Moskowitz A. Towle L. Age-related changes in the latency of the visual evoked potential. Electroencephalogr Clin Neurophysiol 1981; 51: 559-62.

24 Sokol S. Problems of stimulus control in the measurement of peak latency of the pattern visual evoked potential. In: BodisWollner I. ed. Ann NY Acad Sci 1982; 388: 657-61.

25 Burian HM. Pathophysiologic basis of amblyopia and of its treatment. Am J Ophthalmol 1969; 67: 1-12.

26 Hess R. Strabismic and anisometropic amblyopia. Aust J Optom 1979; 62: 4-18. 